\title{
La Scène bâtarde entre Lumières et romantisme, sous la direction de Ph. Bourdin et G. Loubinoux
}

\section{Lise Sabourin}

\section{(2) OpenEdition}

1 Journals

Édition électronique

URL : http://journals.openedition.org/studifrancesi/8944

DOI : 10.4000/studifrancesi.8944

ISSN : 2427-5856

Éditeur

Rosenberg \& Sellier

\section{Édition imprimée}

Date de publication : 1 octobre 2008

Pagination : 465

ISSN : 0039-2944

\section{Référence électronique}

Lise Sabourin, «La Scène bâtarde entre Lumières et romantisme, sous la direction de Ph. Bourdin et G Loubinoux », Studi Francesi [En ligne], 155 (LII | II) | 2008, mis en ligne le 30 novembre 2015, consulté le 10 janvier 2021. URL : http://journals.openedition.org/studifrancesi/8944 ; DOI : https://doi.org/

10.4000/studifrancesi.8944

Ce document a été généré automatiquement le 10 janvier 2021.

\section{(c) $($ ) $\odot$ (8)}

Studi Francesi è distribuita con Licenza Creative Commons Attribuzione - Non commerciale - Non opere derivate 4.0 Internazionale. 


\title{
La Scène bâtarde entre Lumières et romantisme, sous la direction de $\mathrm{Ph}$. Bourdin et $\mathrm{G}$. Loubinoux
}

\author{
Lise Sabourin
}

\section{RÉFÉRENCE}

La Scène bâtarde entre Lumières et romantisme, sous la direction de Ph. BOURDIN et G.

LOUBINOUX, Clermont-Ferrand, Presses Universitaires Blaise Pascal, Service Universités

Culture, «Parcours pluriels», 2004, pp. 334.

1 Dans cet ouvrage consacré aux diverses formes d'arts spectaculaires que la «scène bâtarde» - au sens de sa liberté dans son illégitimité par rapport aux codifications régulées toujours tentées par les doctes (voir la réflexion sur la bâtardise de Jean-Louis JAM, p. 19-23) - a produites du milieu du XVIII ${ }^{\mathrm{e}}$ siècle au romantisme, certains articles touchent directement à la première moitié du XIX ${ }^{\mathrm{e}}$.

2 Deux se penchent sur les questions d'adaptation. Ainsi, Gérard LouBinoux nous incite-til à voir en Castil-Blaze un «Don Quichotte de la bâtardise chez les romantiques» (p. 79-89), tirant sans complexes Mozart, Beethoven, Rossini ou Weber vers la musique populaire, face à l'émergence pourtant de la propriété intellectuelle. Balzac, conscient des succès d'acteurs ménagés par les «manipulations et appropriations» de ses romans sur les scènes parisiennes de 1830 à 1840, qu'étudie Olivier BARA (pp.91-109), sait discerner leur retentissement en faveur de la célébrité des personnages de sa Comédie humaine, tout en obtenant des droits sur ces adaptations fort libres: le vaudeville se permet en effet toutes les audaces - y compris l'oubli du nom de l'auteur originel ou la mutilation du titre - au point de dénaturer l'intrigue en anecdote, le discours social et politique en morale conservatrice.

Quatre autres communications étudient les lieux et bâtiments scéniques dans leur usage par le public. Michèle SAJOU D'ORIA montre les limites de l'impact de la réforme 
napoléonienne de 1807 sur le foisonnement subversif des «tréteaux de la corruption» (pp. 269-282) nés de la loi libertaire de 1791. Cyril, en prenant l'exemple des théâtres du onzième arrondissement théâtral, analyse «les cadres et conditions matérielles de production des spectacles provinciaux pendant le Consulat et l'Empire» (pp. 283-311). Marie-France cussinet fait le tour des "scènes provinciales au début du XIX ${ }^{\mathrm{e}}$ siècle» (pp. 303-311), montrant comment l'ordonnance de Charles X en 1824 a contribué à mettre aux normes de «vrais» théâtres de multiples salles «indignes». Marie-Claire Mussat leur ajoute «le kiosque à musique: une autre scène» (pp.313-319), né de l'héritage orphéonique révolutionnaire, mais promis sous le Second Empire et la Troisième République à des utilisations variées (danses, ouvrages lyriques, musiques militaires) à caractère fortement spectaculaire.

De là naît forcément une réflexion générique que porte en l'occurrence Roxane MARTIN, dans sa question sur «La féerie du Directoire et du Consulat [comme] genèse d'un théâtre romantique» (pp. 255-268) ou, pour la période du Second Empire, Jean-Claude YoN interrogeant la variété de dénominations déployées par «Offenbach l'inclassable» (pp. 203-215). Outre ces deux contributions, on conseillera d'ailleurs aux dixneuviémistes la lecture d'ensemble de cet ouvrage issu de journées d'études auxquelles ont contribué historiens comme spécialistes de littérature française et comparée (même si l'on peut déplorer un assez grand nombre de coquilles, y compris dans la pagination de la table). La plupart des articles portent sur des auteurs du XVIII siècle célèbres (Rétif de la Bretonne, La Harpe) ou méconnus (Jean Fenouillot, les frères Parfaict), sur la terminologie et la pratique des genres juste avant ou pendant la Révolution (l'enfer burlesque, la parodie d'opéra italien, l'opéra comique, le théâtre d'images), mais invitent aussi à la réflexion sur les fondements de la rénovation qu'assumera la génération de 1820-1830 et sur son devenir dans la postérité dramatique (voir l'article de Jean-Marie THOMASSEAU, L'héritage du bâtard ou la féconde lignée du mélodrame d'Antoine à Vilar, pp. 321-334). 